\title{
Acoustic factors versus language factors in short-term memory'
}

\begin{abstract}
Forty five Ss recalled 6-consonant sequences immediately after letter by letter visual presentation. The main factor contributing to ease of recall was withinsequence acoustic confusability. Language habits were relatively unimportant. Single-letter language frequency was unrelated to recall; second order effects made a small but significant contribution.
\end{abstract}

\section{Introduction}

One of the reasons why Ebbinghaus thought so highly of nonsense syllables was the belief that they would be free from meaning and the effects of language experience; memory could thus be studied uncontaminated by verbal habit. That the assumption was false has long been recognised, and for 40 years or more no verbal learning experiments have used nonsense syllables without controlling for association value or meaningfulness, and more recently Underwood \& Schulz (1960) have shown that pronunciablility is also an important determinant of ease of learning letter groups. These measures, though without doubt reliable predictors, are limited by the fact that norms are required before they can be used, that such norms are only available for certain types of letter sequence (e.g. CVCs, CCCs etc.), and that the norms are based on consensus of opinion which needs to be laboriously determined for each type of letter sequence.

In 1958 Miller reported that ease of recall of letter sequences was a function of letter sequence redundancy thus including, probably, most of the earlier measures in one which obviates the need for independently established norms, and which can be applied to any length of sequence. Di Mascio (1959) reported that even single letter frequency was related to memorizability, and Underwood \& Schulz (1960) reported significant correlations between ease of learning single letters as response terms in paired-associate learning, and frequency of occurrence in English. Baddeley (1964) showed that a simple-to-use approximation to second order letter sequence redundancy, which he called predictability, was a highly effective predictor of ease of learning, and since it was based on published tables of digram frequency (Baddeley, Conrad \& Thomson, 1960) required no prior testing.

Baddeley, Conrad \& Hull (1965). measured the predictability of 406 -consonant sequences and obtained a highly significant correlation with ease of short-term memorizing. But when second-order effects were partialled out, a Di Mascio (1959) single-letter frequency measure did not correlate significantly with ease of memorizing.
Coming at verbal learning from an angle completely different from that based on language habits of the kind referred to, Conrad $(1962,1964)$ showed that when consonant sequences are memorized for short-term recall after visual presentation, memory errors correlate highly with listening errors in a conventional intelligibility test for spoken consonants. This result suggested that another factor in determining the ease with which a letter sequence could be learned, would be the acoustic confusability of the letters within the sequence. This prediction was confirmed by Conrad \& Hull (1964) who in the same study showed that when acoustic confusability was held constant, information in the sequence was of minor importance.

However, these measures of acoustic confusability confounded predictability (letter-sequence effects), while the Baddeley, Conrad \& Hull (1965) study of predictability confounded effects of acoustic confusability. The present study was carried out in an attempt to get independent estimates of the effects of these parameters.

\section{Method}

Using all consonants except Z, 40 6-letter sequences were randomly generated with the sole constraints that no letter appeared more than once in a sequence, and letters occurred equally often in each serial position. Sequences were presented letter by letter for immediate recall by means of frame by frame film projection at a rate of $80 / \mathrm{min}$. Unlimited time for written recall was allowed. Ss were 45 paid housewives.

When the sequences had been generated to meet the above constraints, the probability of acqustic confusion was calculated for each sequence from the table of listening data given by Conrad (1964). Similarly the predictability for each sequence was calculated from the table of digrams of the English language in Baddeley, Conrad \& Thomson (1960)。The rank correlation between the two measures was $.18(p>.2)$ 。

\section{Results}

The measure of recall was simply the number of letters in a sequence wrong for the particular serial position. The mean number of errors per subject/sequence was 1.51 (range: .54-3.33). The error data were fitted significantly well $(F=19.23$, df: $2 / 37)$ by the function: $\mathrm{Y}=.895 \mathrm{X}_{\mathrm{O}}+.059 \mathrm{X}_{1}$, where $\mathrm{Y}=$ errors, $\mathrm{X}_{\mathrm{O}}=$ probability of acoustic confusion, $\mathrm{X}_{1}=$ predictability. The acoustic similarity component is significant at the .001 level, the predictability component is significant at the .02 level.

Since letters occurred equi-probably in each serial 
position, the total number of errors per letter was taken as an index of ease of memorizing letters. The productmoment correlation between frequency with which a letter was wrongly recalled and frequency of listening error (Conrad, 1964) was .75, $\mathrm{p}<.001$. When language frequency was correlated with the frequency with which a letter was incorrectly given as response in the memory task, the product-moment correlation was .09. When language frequency was correlated with frequency of the letter being wrongly recalled, the correlation was again about .09.

\section{Discussion}

It seems adequately shown that for short-term storage of consonant sequences, encoding of presented material depends much more on what the individual letters sound like, than on the frequency with which they have previously been met in the course of using language. Single-letter frequency seems irrelevant to the task and the results sharply qualify the SPEW hypothesis of Underwood \& Schulz (1960) which asserts that the availability of verbal units as responses in new associative connections depends on the frequency with which they have previously been experienced. However, when the index of experience is based on higher order sequence relationships it does become more important for memory. Nevertheless, Conrad (1963) has shown that when letter sequence redundancy is very high and relatively homogeneous, as with common words, the acoustic properties of the word still dominate. S's encoding strategy is probably dependent on the time he has available for it.

\section{References}

Baddeley, A. D. Immediate memory and the "perception" of letter sequences. Quart. J. exp. Psychol., 1964, 16, 364-367.

Baddeley, A. D., Conrad, R., \& Hull, A. J. Predictability and immediate memory for consonant sequences. Quart. J. exp. Psychol., $1965,17,175-177$.

Baddeley, A. D., Conrad, R., \& Thomson, W. E. Letter structure of the English language. Nature, 1960, 186, 414-416.

Conrad, R. An association between memory errors and errors due to acoustic masking of speech. Nature, 1962, 193, 1314-1315.

Conrad, R. Acoustic confusions and memory span for words. Nature, 1963, 197, 1029-1030.

Conrad, R. Acoustic confusions in immediate memory. Brit. J. Psychol., 1964, 55, 75-84.

Conrad, R., \& Hull, A. J. Information, acoustic confusion and memory span. Brit. J. Psychol., 1964, 55, 429-432.

Di Mascio, A. Learning characteristics of nonsense syllables: A function of letter frequency. Psychol. Rep., 1959, 5, 585-591.

Miller, G. A. Free recall of redundant strings of letters. J. exp. Psychol., 1958, 56, 485-491.

Underwood, B. J., \& Schulz, R. W. Meaningfulness and verbal learning. New York: Lippincott, 1960.

\section{Note}

1. This article was written while the senior author (R. Conrad) held a position of Visiting Scientist at the Human Performance Center, Department of Psychology, University of Michigan. This post was supported by the Advanced Research Projects Agency, Department of Defense, and monitored by the Air Force Office of Scientific Research under Contract No. AF 49(638)-1235. 